\title{
Effect of Extrinsic Perturbation by Transverse Pressure, Bending and Tension Birefringence
}

\author{
Dr. C. M. Jadhao \\ Principal, MGI COET, Shegaon-444303 (MS), India
}

\begin{abstract}
Birefringence and polarization dispersion caused by elliptical core, twist, pure bending, transverse pressure and axial tension are studied by treating these deformations as perturbations to step-index single-mode fiber with a round core. These effects are formulated in terms of fiber structure and perturbation parameters and are compared comprehensively. The results show that as the transverse pressure is increased, the birefringence also increases. When transverse pressure is $0.8 \mathrm{KgW} / \mathrm{m}$ is applied the delta beta is $2.6731 \mathrm{rad} / \mathrm{m}$ and $\mathrm{DGD}$ is $-1.835 \mathrm{ps} / \mathrm{Km}$ and it increased to $-4.5761 \mathrm{rad} / \mathrm{m}$ and $-3.7682 \mathrm{ps} / \mathrm{Km}$ respectively when transverse pressure in increased doubled. This also shows that the transverse pressure is more dominated to polarization and remains steady but birefringence varies to the wavelength. The results shows that as the bending radius increased the delta and DGD decreased and polarization is steady for the corresponding bending and wavelength but the delta beta is varying with wavelength for the corresponding bending radius, the Delta beta is $-0.0527 \mathrm{rad} / \mathrm{m}$ and DGD is $-0.0440 \mathrm{ps} / \mathrm{Km}$ for the bending radius of $0.20 \mathrm{~m}$ and this increased to $-0.1463 \mathrm{rad} / \mathrm{m}$ and $0.1208 \mathrm{ps} / \mathrm{Km}$ respectively as bending radius decrease to $0.12 \mathrm{~m}$. The results show that as spooled tension is increased the delta beta and DGD increases and also these increases as bending radius decreased. The Delta beta is $-2.6909 \mathrm{rad} / \mathrm{m}$ and $\mathrm{DGD}$ is $-2.2148 \mathrm{ps} / \mathrm{Km}$ for the spooled tension of $0.1936 \mathrm{~N}$ and it increases to $-4.8969 \mathrm{rad} / \mathrm{m}$ and $-4.0301 \mathrm{ps} / \mathrm{Km}$ respectively for tension increased to $0.3658 \mathrm{~N}$ at bending radius of $0.1 \mathrm{~m}$. The delta beta and DGD decreases to $-1.2928 \mathrm{rad} / \mathrm{m},-1.0639 \mathrm{ps} / \mathrm{Km}$ for tension $=0.1936 \mathrm{~N} \mathrm{and}-2.3958 \mathrm{rad} / \mathrm{m},-$ 1.9715 for tension $0.3658 \mathrm{~N}$ respectively when the bending radius increased to $0.20 \mathrm{~m}$.
\end{abstract}

Keywords: FiberOptics, Birefringes, PMD, Bending, T Pressure

\section{Extrinsic Perturbation Birefringence}

Birefringence can also be created in a fiber when it is subjected to external forces in handling or cabling. Such extrinsic sources of birefringence include lateral stress, fiber bending and fiber twisting ${ }^{1}$. All three of these mechanisms are usually present to some extent in spooled and fieldinstalled telecommunications fiber ${ }^{2}$. Extrinsic sources of birefringence include lateral stress, fiber bending and fiber twisting and the tension-coiled birefringence results from the lateral force exerted by the drum on the fiber in reaction to the tensile force ${ }^{3}$. Thus the analysis of following extrinsic perturbations is carried out

a) Lateral stress or Transverse pressure birefringence

b) Bending birefringence

c) Fiber spooled with tension birefringence

1.1 Analysis of Extrinsic perturbation by Lateral stress or Transverse

When two equal and opposite forces p act across an axis of a fiber with a diameter $\mathrm{d}$, the birefringence induced is linear. The fast axis of birefringence is aligned with the axis defined by the two opposite forces ${ }^{5}$. When force $\mathrm{p}$ applied to the fiber known as transverse pressure and the analysis of this extrinsic perturbation is obtained by using equations 1 and 2 for different transverse pressure $\mathrm{p}$ applied in $\mathrm{KgW} / \mathrm{m}$ and results obtained are as shown in figure 1 and Table 1 . The results show that as the transverse pressure is increased, the birefringence also increases. When transverse pressure is 0.8 $\mathrm{KgW} / \mathrm{m}$ is applied the delta beta is $-2.6731 \mathrm{rad} / \mathrm{m}$ and DGD is $-1.835 \mathrm{ps} / \mathrm{Km}$ and it increased to $-4.5761 \mathrm{rad} / \mathrm{m}$ and $3.7682 \mathrm{ps} / \mathrm{Km}$ respectively when transverse pressure in increased doubled. This also concludes that the transverse pressure is more dominated to polarization and remains steady but birefringence varies to the wavelength ${ }^{6}$.
Table 1: Birefringence Induced by Extrinsic Perturbation by Transverse Pressure $(\lambda=1.55 \mu \mathrm{m})$

\begin{tabular}{|c|c|c|}
\hline $\begin{array}{c}\text { Transverse pressure } \\
(\mathrm{KgW} / \mathrm{m})\end{array}$ & $\begin{array}{c}\text { Delta Beta } \\
(\mathrm{rad} / \mathrm{m})\end{array}$ & $\begin{array}{c}\text { DGD } \\
(\mathrm{ps} / \mathrm{km})\end{array}$ \\
\hline 0.8 & -2.6731 & -1.8353 \\
\hline 1.0 & -2.8346 & -2.3248 \\
\hline 1.2 & -3.3973 & -2.8166 \\
\hline 1.4 & -3.8743 & -3.2976 \\
\hline 1.6 & -4.5761 & -3.7687 \\
\hline
\end{tabular}

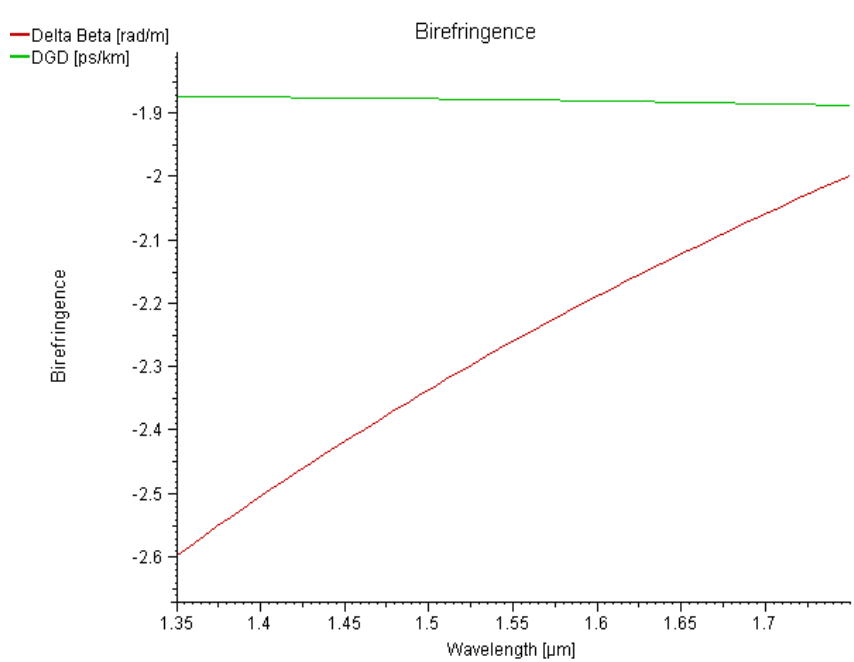

Figure 1(a): Birefringence Induced by Extrinsic Perturbation by Transverse Pressure with Lateral force ( $p=$ $0.8 \mathrm{KgW} / \mathrm{m}$ ) 


\section{International Journal of Science and Research (IJSR) \\ ISSN (Online): 2319-7064}

Index Copernicus Value (2013): 6.14 | Impact Factor (2014): 5.611

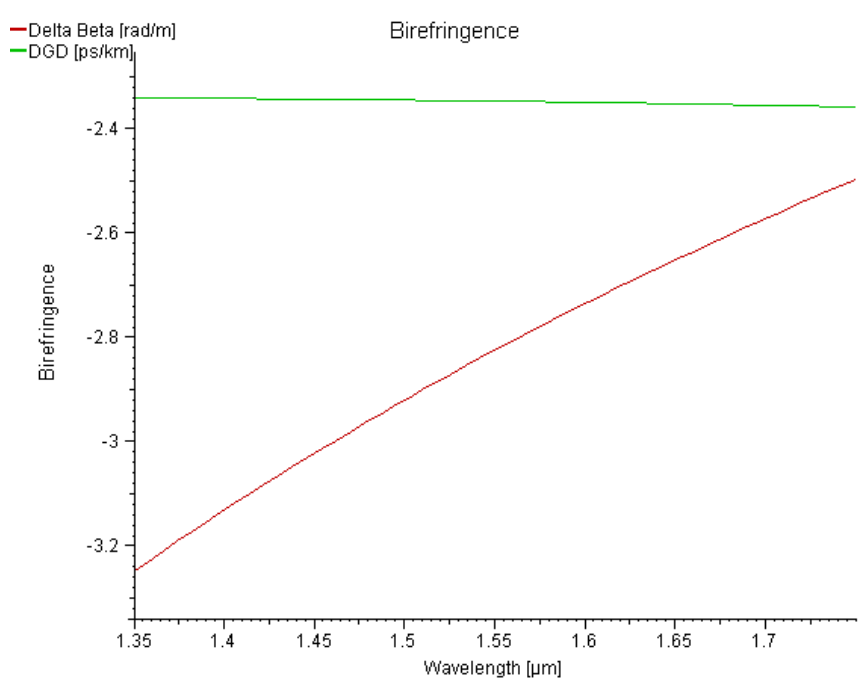

Figure 1(b): Birefringence Induced by Extrinsic Perturbation by Transverse Pressure with Lateral force $(p=$

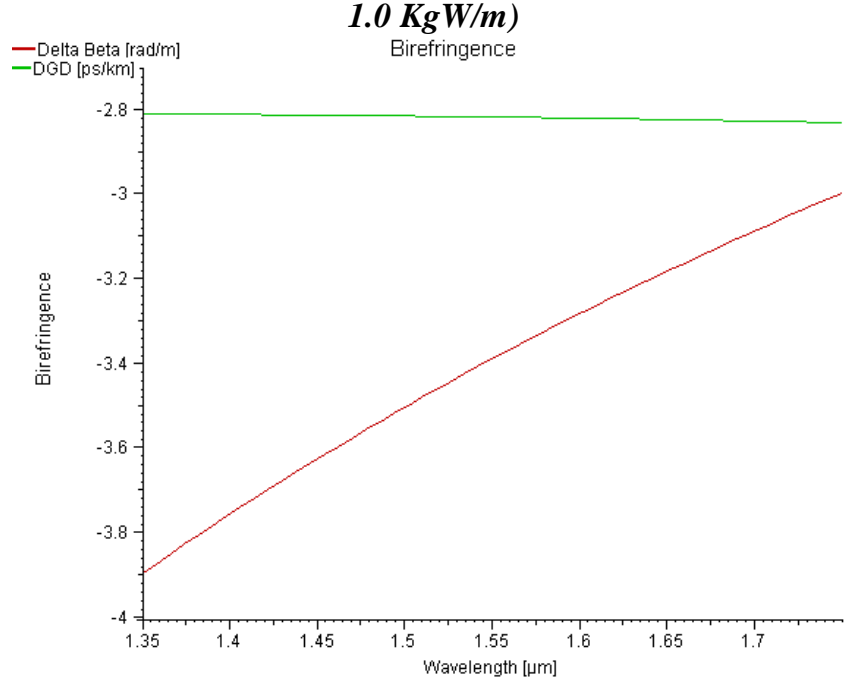

Figure 1(c): Birefringence Induced by Extrinsic Perturbation by Transverse Pressure with Lateral force ( $p=$

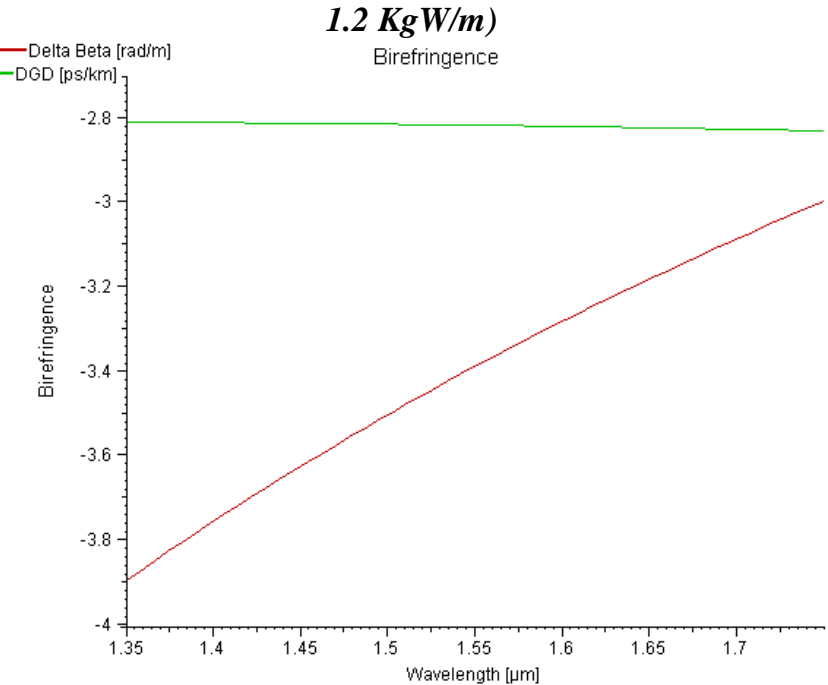

Figure 1(d): Birefringence Induced by Extrinsic Perturbation by Transverse Pressure with Lateral force $(p=$ $1.4 \mathrm{KgW} / \mathrm{m})$

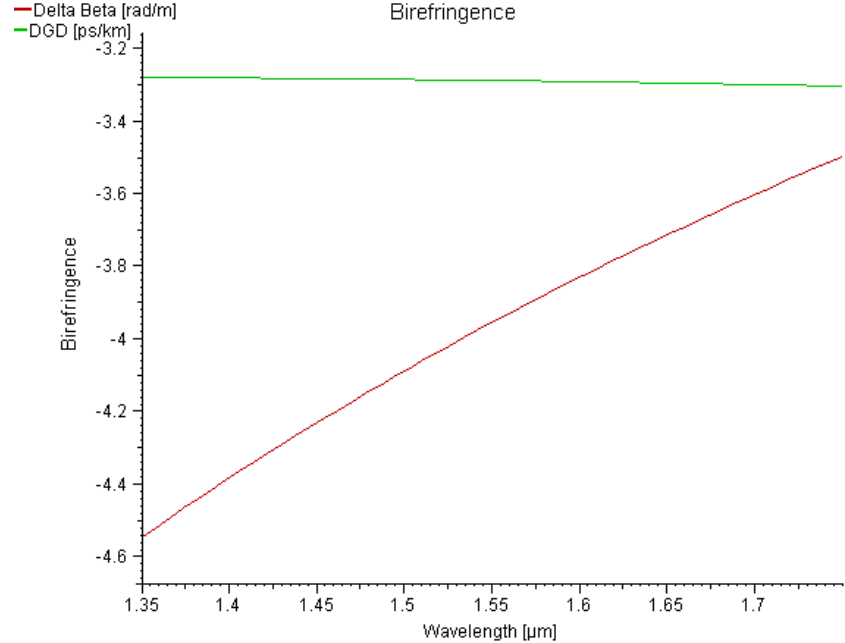

Figure 1(e): Birefringence Induced by Extrinsic Perturbation by Transverse Pressure with Lateral force ( $p=$ $1.6 \mathrm{KgW} / \mathrm{m}$ )

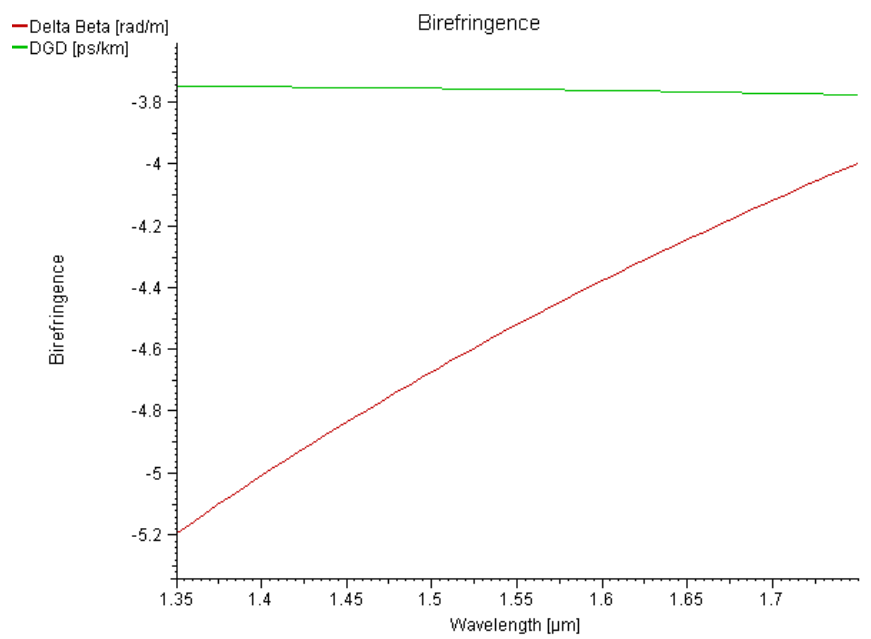

Figure 2(a): Birefringence(Delta Beta) Induced by Extrinsic Perturbation by different bending radius $\mathrm{Rb}$

\subsection{Analysis of Extrinsic perturbation by Bending Birefringence}

Bending on a fiber with a bending radius $\mathrm{R}>>$ a (fiber core) gives rise to a linear birefringence ${ }^{7}$. The fast axis of birefringence is perpendicular to the bending plane. The slow axis is aligned with the bending radius. The experimental results are obtained for extrinsic bending perturbation birefringence by using the equation 3 and 4 and results obtained are as shown in figure 2 and Table 2. The results shows that as the bending radius increased the delta and DGD decreased and polarization is steady for the corresponding bending and wavelength but the delta beta is varying with wavelength for the corresponding bending radius, the Delta beta is $-0.0527 \mathrm{rad} / \mathrm{m}$ and DGD is -0.0440 $\mathrm{ps} / \mathrm{Km}$ for the bending radius of $0.20 \mathrm{~m}$ and this increased to $-0.1463 \mathrm{rad} / \mathrm{m}$ and $-0.1208 \mathrm{ps} / \mathrm{Km}$ respectively as bending radius decrease to $0.12 \mathrm{~m}$. These experimental results are having good agreement with theory ${ }^{4}$. 


\section{International Journal of Science and Research (IJSR) \\ ISSN (Online): 2319-7064 \\ Index Copernicus Value (2013): 6.14 | Impact Factor (2014): 5.611}

Table 2: Birefringence Induced by Extrinsic Perturbation by $\operatorname{BENDING}(\lambda=1.55 \mu \mathrm{m})$

\begin{tabular}{|c|c|c|}
\hline Bending Radius $(\mathrm{m})$ & Delta Beta $(\mathrm{rad} / \mathrm{m})$ & $D G D(\mathrm{ps} / \mathrm{Km})$ \\
\hline 0.12 & -0.1463 & -0.1208 \\
\hline 0.14 & -0.1075 & -0.0888 \\
\hline 0.16 & -0.0823 & -0.0680 \\
\hline 0.18 & -0.0651 & -0.0537 \\
\hline 0.20 & -0.0527 & -0.0439 \\
\hline
\end{tabular}

\subsection{Analysis of Extrinsic perturbation by Bending under Tension Birefringence}

If we consider a pure axial stress applied to the fiber, simple symmetry considerations show that there is no induced birefringence. But winding a fiber with axial tension ,ffe onto a drum introduces an additional linear birefringence that adds to the bending birefringence. This tension-coiled birefringence results from the lateral force exerted by the drum on the fiber in reaction to the tensile force ${ }^{8}$. Using the equation 5 and 6 the experimental results have been carried out. The results are obtained by applying the spooled tension under different bending conditions for example the results are obtained for bending radius of $0.1,0.15$, and 0.2 , are as shown in figure 3,4 and 5 respectively and Table 3

Table 3: Birefringence Induced by Extrinsic Perturbation by Spooled tension for diferent bending radius $(\lambda=1.55 \mu \mathrm{m})$

\begin{tabular}{|c|c|c|c|c|c|c|}
\hline \multirow{2}{*}{$\begin{array}{c}\text { Tension } \\
(\mathrm{N})\end{array}$} & \multicolumn{2}{|c|}{$\mathrm{Rb}=0.1$} & \multicolumn{2}{c|}{$\mathrm{Rb}=0.15$} & \multicolumn{2}{c|}{$\mathrm{Rb}=0.2$} \\
\cline { 2 - 8 } & $\begin{array}{c}\text { Delta } \\
\text { Beta } \\
\mathrm{rad} / \mathrm{m}\end{array}$ & $\begin{array}{c}\mathrm{DGD} \\
\mathrm{ps} / \mathrm{Km}\end{array}$ & $\begin{array}{c}\text { Delta } \\
\text { Beta } \\
\mathrm{rad} / \mathrm{m}\end{array}$ & $\begin{array}{c}\mathrm{DGD} \\
\mathrm{ps} / \mathrm{Km}\end{array}$ & $\begin{array}{c}\text { Delta } \\
\text { Beta } \\
\mathrm{rad} / \mathrm{m}\end{array}$ & $\begin{array}{c}\mathrm{DGD} \\
\mathrm{ps} / \mathrm{Km}\end{array}$ \\
\hline 0.1936 & -2.6909 & -2.2148 & -1.7471 & -1.4379 & -1.2928 & -1.0639 \\
\hline 0.2943 & -3.9809 & -3.2763 & -2.6071 & -2.1456 & -1.9378 & -1.5947 \\
\hline 0.3658 & -4.8969 & -4.0301 & -3.2178 & -2.6481 & -2.3958 & -1.9715 \\
\hline
\end{tabular}

The results show that as spooled tension is increased the delta beta and DGD increases and also these increases as bending radius decreased ${ }^{9}$. The Delta beta is $-2.6909 \mathrm{rad} / \mathrm{m}$ and DGD is $-2.2148 \mathrm{ps} / \mathrm{Km}$ for the spooled tension of $0.1936 \mathrm{~N}$ and it increases to $-4.8969 \mathrm{rad} / \mathrm{m}$ and $-4.0301 \mathrm{ps} / \mathrm{Km}$ respectively for tension increased to $0.3658 \mathrm{~N}$ at bending radius of $0.1 \mathrm{~m}$. The delta beta and DGD decreases to $-1.2928 \mathrm{rad} / \mathrm{m},-1.0639$ $\mathrm{ps} / \mathrm{Km}$ for tension $=0.1936 \mathrm{~N}$ and $-2.3958 \mathrm{rad} / \mathrm{m},-1.9715$ for tension $0.3658 \mathrm{~N}$ respectively when the bending radius increased to $0.20 \mathrm{~m}$. These results are having good agreement with theory ${ }^{4}$.

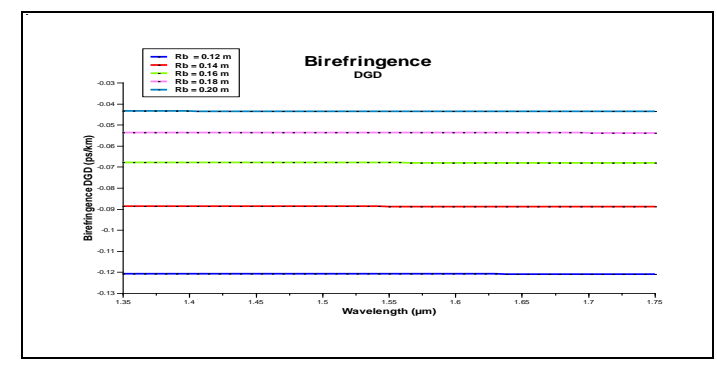

Figure 2(b): Birefringence(DGD) Induced by Extrinsic Perturbation by different bending radius $\mathrm{Rb}$

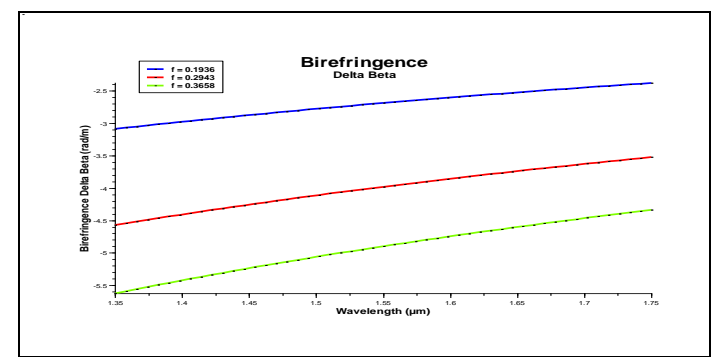

Figure 3(a): Delta Beta Induced by Extrinsic Perturbation by Fiber spooled with different axial tension (f) with Bending radius of $\mathrm{Rb}=0.10 \mathrm{~m}$

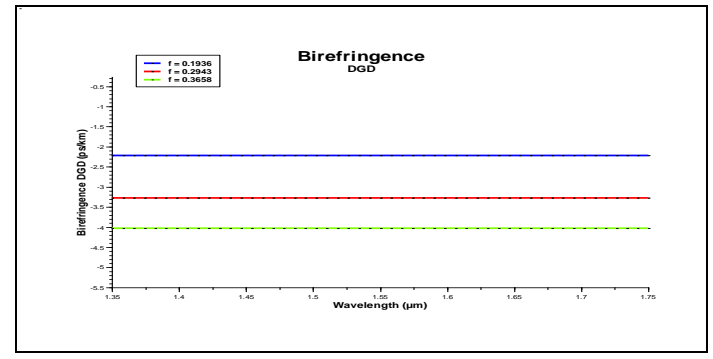

Figure 3(b):DGD Induced by Extrinsic Perturbation by Fiber spooled with different axial tension (f) with Bending radius of $\mathrm{Rb}=0.10 \mathrm{~m}$

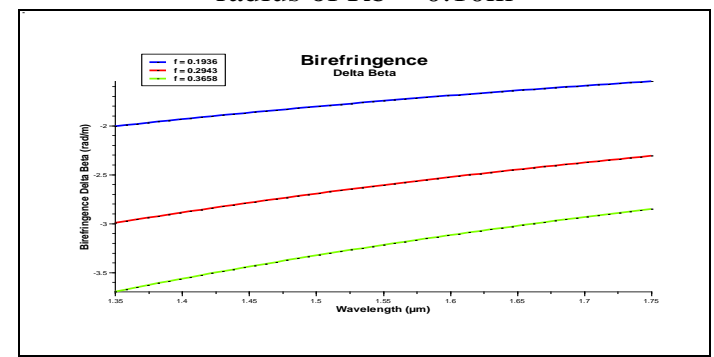

Figure 4(a): Delta Beta Induced by Extrinsic Perturbation by Fiber spooled with different axial tension (f) with Bending radius of $\mathrm{Rb}=0.15 \mathrm{~m}$

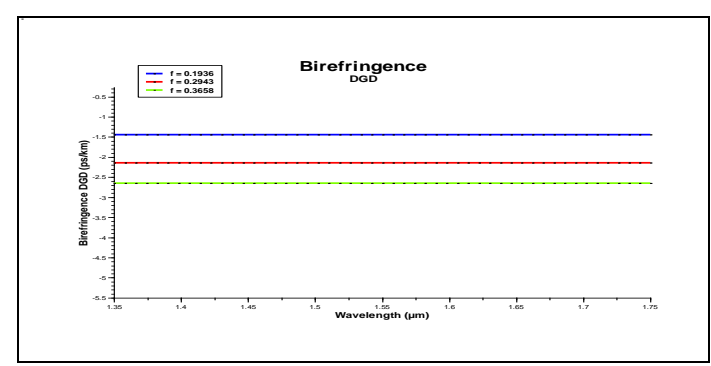

Figure 4(b):DGD Induced by Extrinsic Perturbation by Fiber spooled with different axial tension (f) with Bending radius of $\mathrm{Rb}=0.15 \mathrm{~m}$

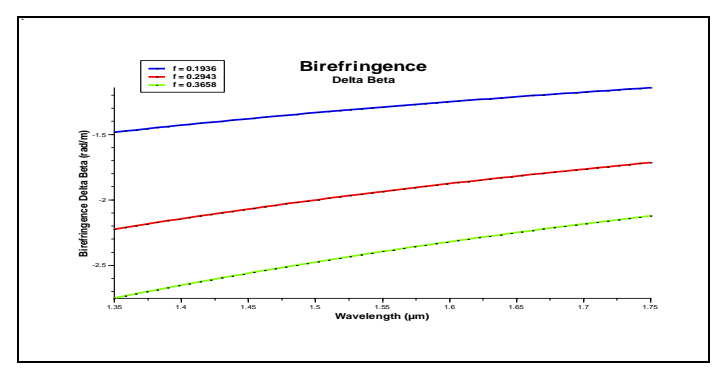

Figure 5(a): Delta Beta Induced by Extrinsic Perturbation by Fiber spooled with different axial tension (f) with Bending radius of $\mathrm{Rb}=0.2 \mathrm{~m}$ 


\section{International Journal of Science and Research (IJSR) \\ ISSN (Online): 2319-7064}

Index Copernicus Value (2013): 6.14 | Impact Factor (2014): 5.611

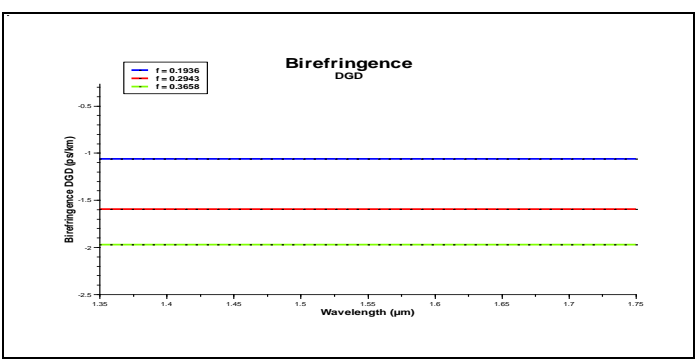

Figure 5(b):DGD Induced by Extrinsic Perturbation by Fiber spooled with different axial tension (f) with Bending radius of $\mathrm{Rb}=0.2 \mathrm{~m}$

\section{Conclusion}

Birefringence and polarization dispersion caused by elliptical core, twist, pure bending, transverse pressure and axial tension are studied by treating these deformations as perturbations to step-index single-mode fiber with a round core. These effects are formulated in terms of fiber structure and perturbation parameters and are compared comprehensively. Birefringence depends strongly on the factors viz-elliptical core, twist, pure bending, and transverse pressure, while polarization dispersion depends on the factors viz-elliptical core, pure bending and transverse pressure ${ }^{94}$. Birefringence and polarization dispersion caused by several elastic deformations and an elliptical core deformation in step-index single-mode fibers have been formulated and compared.

\section{References}

[1] R.D. Birch, M.P. Varnham, D. N. Payne, K. Okamoto, "Fabrication of a Stress-Guiding optical fiber", Electronics letter, $13^{\text {th }}$ Oct 1983, Vol. 19, No 21.

[2] T. Kimura, " Factors affecting fiber optic transmission quality”, J. Of Light wave Technology Vol.6 No. 5 May 1988.

[3] S. R. Norman, D.N. Payne, M.J. Adams, "Fabrication of single mode fibers Exhibiting Extremely low polarization Birefringence", Electronics letter, $24^{\text {th }}$ may 1978, Vol. 15, No. 11.

[4] J. Sakai and T. Kimura, "Birefringence and Polarization characteristics of single mode optical fibers under Elastic deformations", J. Of Quantum Electronics Vol. QE-17, No. 6 June 1981.

[5] N. Uesugi, T. Kuwabara, M. Ohashi, Y. Ishida, N. Uchida, "Stress and temperature effect on optical loss increase for phosphor-doped silica fiber in the long wavelength region", Electronics Letter $29^{\text {th }}$ Sep 1983 vol.19 No.20.

[6] H. Renner, "Impact of UV-induced mode-field deformation on residual stress birefringence in single mode fibers", Optics communication, 244 (2005) 131135.

[7] M.P. Varnham, D.N. Payne, R.D. Birch, E.J. Tarbox, "Bend Behavior of polarizing optical fibers ", Electronics Letter $18^{\text {th }}$ Aug 1983, vol. 19, No. 17.

[8] N Imoto, N Yoshizawa, J sakai and $\mathrm{H}$ Tsuchiya, "Birefringence in single made optical Fiber due to Elliptical core Deformation and stress Anisotropy “, J. Quantum Electronics, Vol. QE-16, No.11 1980 PP 1267.
[9] T. Hosaka, K. Okamoto, T. Miya, Y. Sakai, T. Edahiro, "Low-loss single polarization fibers with asymmetrical strain Birefringence", Electronics Letter, $23^{\text {rd }}$ July 1981 , Vol. 17, No. 15. 